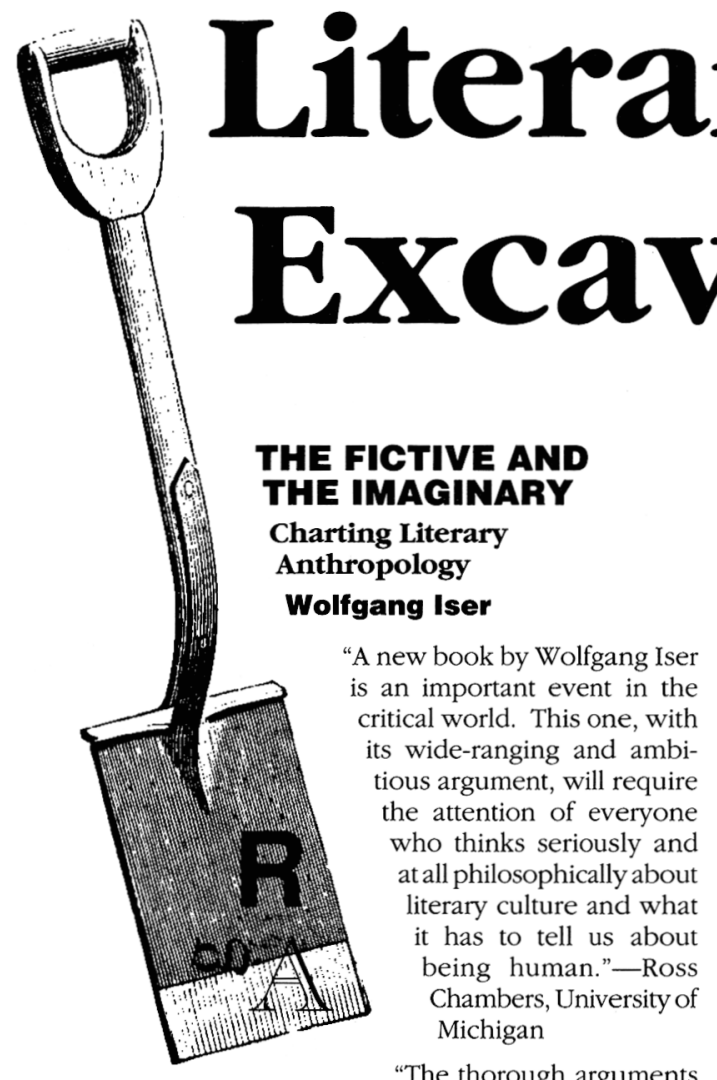

and many arresting formulations that prepare for Iser's concluding position insure that it will be heeded and debated by anyone seriously concerned with the character of literature and its place in culture."-John Paul Riquelme, Boston University

$\$ 15.95$ paperback $\$ 55.00$ hardcover

\section{Now in paperback}

\section{PROSPECTING}

From Reader Response to Literary Anthropology Wolfgang Iser

"An important transitional book, usefully summarizing the past and thoughtfully mapping out the future of a significant critic's theoretical project."-Modern Pbilology

"Prospecting contains fine examples of Iser's ability to relate theoretical issues to analyses of individual works. It will deservedly enhance his reputation as a critic and theorist who writes with equal skill and learning about Renaissance, Neoclassic, and modernist texts."-Ralph Cohen, University of Virginia

$\$ 14.95$ paperback

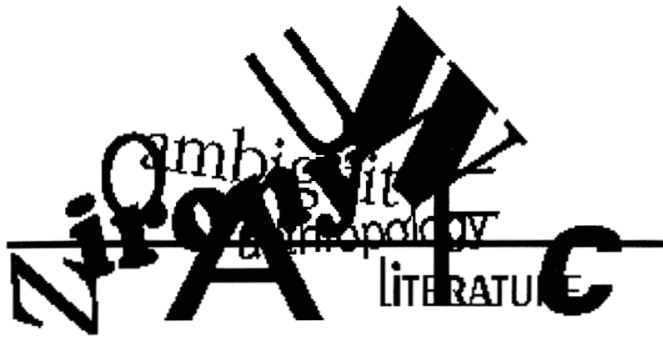

\section{THE ADVENTURE OF DIFFERENCE}

Philosophy after Nietżsche and Heidegger

\section{Gianni Vattimo}

translated by Cyprian Blamires, with the assistance of Thomas Harrison

Gianni Vattimo examines the notion of "difference" in scientific knowledge and contemporary mass society and illustrates the importance of Nietzsche and Heidegger in both formulating the concept and exploring its implications for current debates on the nature of modernity.

Parallax: Re-visions of Culture and Society Stephen G. Nichols, Gerald Prince, and Wendy Steiner, Series Editors

$\$ 29.95$ hardcover

\section{THE OFFICE OF THE SCARLET LETTER \\ Sacvan Bercovitch}

Recipient of the Modern Language Association's James Russell Lowell Prize

"Goes a long way to proving that any literary masterpiece, read with sympathy and intelligence, works to re-establish the connections between the work of art and the life and thought of its time."-James R. Mellow, Times Literary Supplement

Parallax: Re-visions of Culture and Society

Stephen G. Nichols, Gerald Prince, and Wendy Steiner, Series Editors

\section{$\$ 12.95$ paperback}

\section{PRINCES TO ACT}

Royal Audience and Royal Performance, 1578-1792

\section{Matthew H. Wikander}

Matthew Wikander describes how theater and monarchy in the seventeenth and eighteenth centuries existed in mutual dependency and mutual mistrust, leading to performances that both affirmed and challenged the social boundaries between monarch and actor, audience and performer. He explores plays by Shakespeare, Davenant, Corneille, Moliere, Racine, Voltaire, and others

$\$ 48.95$ hardcover

\section{JOHNS HOPKINS}

The Johns Hopkins University Press 701 West 40th Street, Suite 275, Baltimore, Maryland 21211 To order, call 1-800-537-5487. 


\section{Serenity in Crisis}

A Preface to Paul de Man, 1939-1960

Ortwin de Graef

"The debates about deconstruction may now be waning, but the historical and cultural analysis of the phenomenon is just beginning. De Graef's book will be the beginning of a serious study of this movement as an intellectual force."-Sander Gilman, author of Inscribing the Other.

$\$ 35.00$ cloth

\section{The Mirror and the Word}

Modernism, Literary Theory, and Georg Trakl Eric B. Williams

"Williams has found an ingeniously indirect method for dealing with powerful and conservative voices in Trakl criticism, a method that unburdens the debate of its weighty pomposity and elicits delight from readers familiar with the critical context."Francis Michael Sharp, author of The Poet's Madness: A Reading of Georg Trakl. $\$ 40.00$ cloth

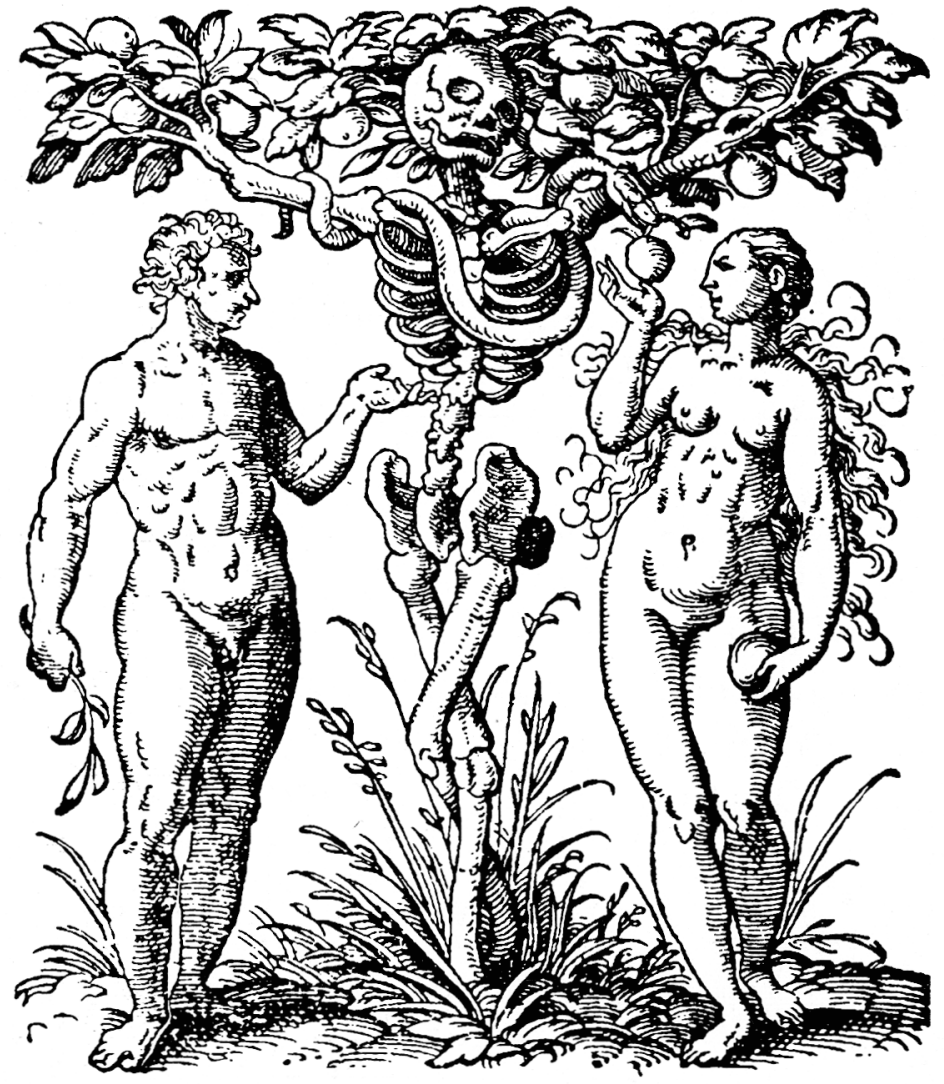

\section{Reading the Classics and Paradise Lost}

William M. Porter

In the twentieth century the classics have become mere "background." As a consequence, William M. Porter argues, not only is the foundational dimension of Milton's poetry now hardly visible, even to scholars, but the potential of Milton's poetry to revitalize the reading of the classics has been diminished. Porter demonstrates that Milton's genuine allusions to the classics, while fewer than has been supposed, are rich with wit, irony, and thought that can be grasped only by a reader with a double perspective. $\$ 30.00$ cloth

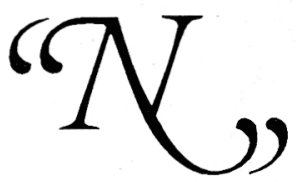

University of Nebraska Press 901 North 17th St. • Lincoln, NE 68588-0520 • 800-755-1105 